\title{
Prospects for reconstructing the Atlantic meridional overturning from cross-basin density estimates
}

Jean Lynch-Stieglitz' ${ }^{1}$ J. HiRschi² ${ }^{2}$, O. Marchal ${ }^{3}$ and U. Ninnemann ${ }^{4}$

${ }^{1} S c h o o l$ of Earth and Atmospheric Sciences, Georgia Institute of Technology, Atlanta, USA; jean@eas.gatech.edu.

${ }^{2}$ National Oceanography Centre, University of Southampton, UK; ${ }^{3}$ Woods Hole Oceanographic Institution, USA; ${ }^{4}$ Department of Earth Sciences and Bjerknes Centre for Climate Research, University of Bergen, Norway

In much the same way that a sharp contact between warm and cold air masses on a weather map suggests the presence of strong winds, the horizontal differences in seawater density (determined by both temperature and salinity) can tell us about the strength of the ocean currents. Specifically, because large-scale ocean flows are generally in geostrophic and hydrostatic balance, the vertical differences (shear) in horizontal velocities can be determined from the horizontal density gradients. This approach, based on detailed density measurements, has underpinned most of the efforts to quantify elements of the modern ocean circulation over the last century. While closely spaced density measurements are necessary to construct a detailed picture of ocean currents, the meridional circulation integrated zonally across a given basin can be determined from density measurements at the ocean margins (Cunningham et al., 2007; Hirschi and Marotzke, 2007; Marotzke et al., 1999). This has allowed, for example, continuous monitoring of the modern Atlantic Meridional Overturning Circulation (AMOC) at $26^{\circ} \mathrm{N}$ (Cunningham et al., 2007). LynchStieglitz et al. (1999a; 1999b) showed how the oxygen isotopic composition $\left(\delta^{18} \mathrm{O}\right)$ of benthic foraminifers from sediments could be used to estimate water density", and hence reconstruct the horizontal flow in the upper ocean for times in the past.
They suggested that density estimates at ocean boundaries could be used to reconstruct the shear in the integrated meridional overturning circulation below the wind-driven Ekman layer near the surface (Lynch-Stieglitz, 2001). In a recent paper, Huybers et al. (2007) examined the ability of paleoceanographic tracers to constrain meridional circulation rates in an idealized basin. They found that when data can only be obtained along the seafloor (as is the case for paleoceanographic reconstructions), density provides an important integrative measure of circulation. However, they highlight the need for more accurate paleo-density estimates. Here, we report on recent progress in reconstructing the AMOC from paleo-density estimates. Many of these studies and ideas emerged from the discussions of the Working Group on Past Ocean Circulation, jointly sponsored by IMAGES and SCOR.

\section{LGM South Atlantic water density}

In today's South Atlantic, seawater density in the upper $2 \mathrm{~km}$ is greater along the eastern margin than along the western (Fig. 1a). This zonal density gradient reflects the shear of the AMOC at these depths, with a northward flow between the surface and $1 \mathrm{~km}$ water depth, and a southward flow ("North Atlantic Deepwater") between 1 and $2 \mathrm{~km}$ water depth. Lynch-Stieglitz et al. (2006) found that this density gradient is reflected in the higher $\delta^{18} \mathrm{O}$ (colder and/ or saltier waters) values of foraminifers found in surface sediments on the eastern margin relative to those from the western margin (Fig. 1b). However, they found that foraminifers from sediments corresponding to the LGM showed a reduced gradient, with perhaps slightly higher $\delta^{18} \mathrm{O}$ values on the western margin. We do not know the precise relationship between the $\delta^{18} \mathrm{O}$ of foraminifers and water density for the LGM in the South Atlantic. However, on both sides of the basin, $\delta^{18} \mathrm{O}$ increases with depth, suggesting that like today, higher $\delta^{18} \mathrm{O}$ in benthic foraminifers is associated with higher seawater density. This would imply that the shear associated with the AMOC was significantly reduced or even reversed in the South Atlantic at the LGM. This is incompatible with either a strong, deep (similar to modern) AMOC shown by some coupled ocean-atmosphere models for the LGM, or a shallower but still strong overturning cell shown in other models and inferred from sediment-based estimates of nutrient distributions during the LGM.

Gebbie and Huybers (2006) raise the possibility that interpreting glacial foraminiferal $\delta^{18} \mathrm{O}$ in terms of water density could be misleading if there were very different water mass properties on either side of the Atlantic Ocean. Given today's relationship between the $\delta^{18} \mathrm{O}$ of water

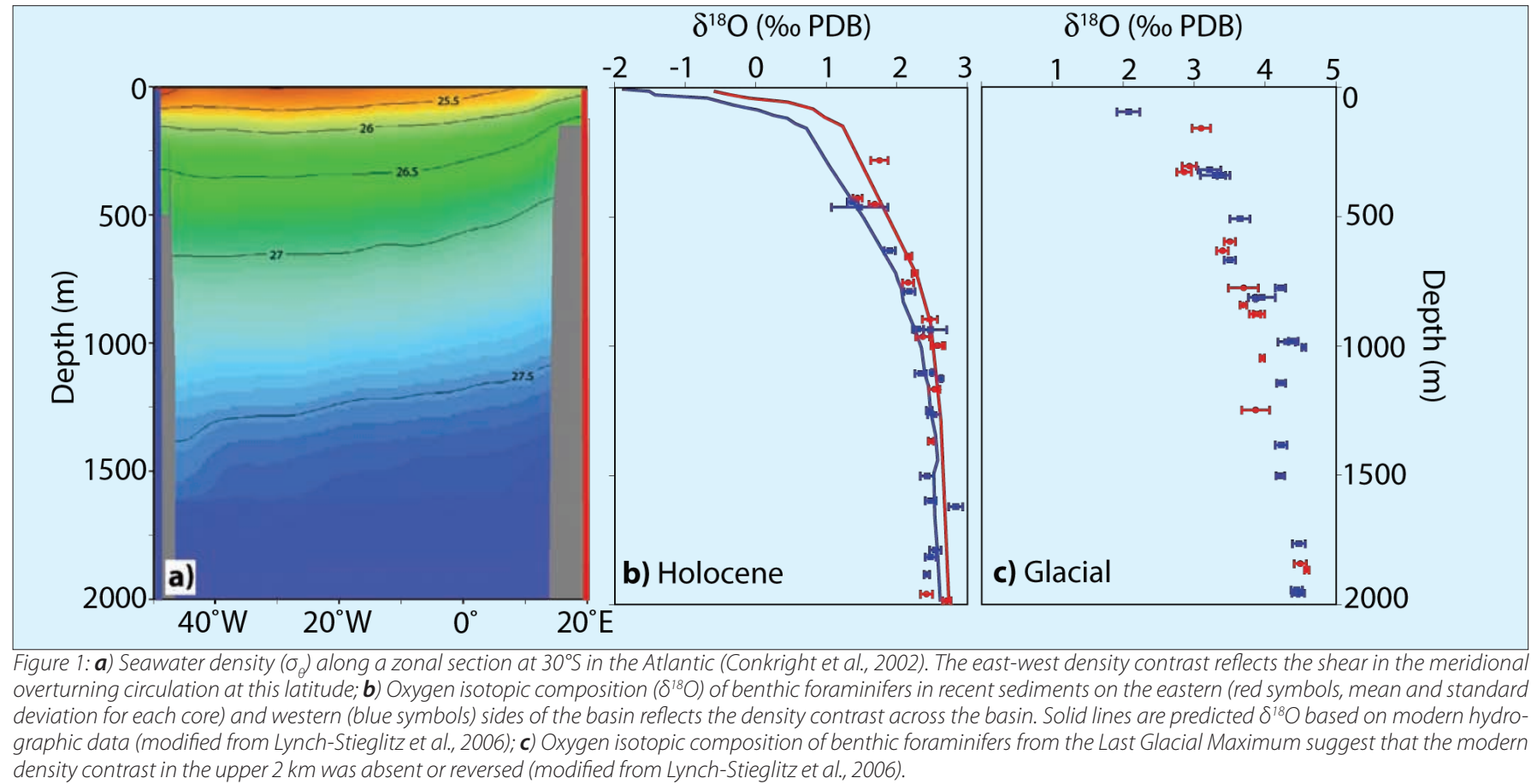


and salinity, they find that waters would need to be $3^{\circ} \mathrm{C}$ warmer and $0.7 \%$ saltier on the eastern margin than on the western margin, in order for the benthic $\delta^{18} \mathrm{O}$ data to be compatible with a density contrast (and circulation) unchanged from today. Today, the water masses on either side of the South Atlantic have similar temperature and salinity properties, due to the narrow ocean basin, effective mixing along isopycnals in the upper ocean, and the lack of a strong water mass source nearby (Fig. 2a). It would seem unlikely to have such a dramatic change in water mass properties (similar to the impact of the Mediterranean Outflow in the North Atlantic) without a significant change in circulation. However, one cannot easily discount the possibility of more subtle differences in the relationship between $\delta^{18} \mathrm{O}$ of water and salinity on the western and eastern sides of the glacial South Atlantic, which could produce a different relationship between benthic $\delta^{18} \mathrm{O}$ and water density on either side of the basin. The work of Gebbie and Huybers (2006) clearly points to the necessity to better constrain water mass properties for more accurate density reconstructions.

\section{Prospects for improving paleo- density estimates}

While the oxygen isotopic composition of benthic foraminifers can be used to estimate water density, it cannot uniquely constrain water density in the geological past. Any uncertainty in regarding the relationship between the $\delta^{18} \mathrm{O}$ of foraminiferal calcite and water density will translate into uncertainty in estimates of paleo-density and paleo-flow. Better estimates of paleodensity would require the availability of independent estimates of salinity and temperature. The chlorinity of pore water in deep sea sediments has been used to estimate the salinity of bottom waters during the LGM, and the $\delta^{18} \mathrm{O}$ of pore water coupled with the $\delta^{18} \mathrm{O}$ of foraminiferal calcite has yielded estimates of LGM bottom water temperatures (Adkins et al., 2002). Although diffusion of pore water properties within the sediments limits the temporal resolution of this approach, such measurements can help provide constraints on the density of bottom waters during the LGM. This information can also help us better interpret the higher time-resolution records obtained from the $\delta^{18} \mathrm{O}$ in foraminiferal calcite. However, such an approach would require many more measurements of chlorinity and $\delta^{18} \mathrm{O}$ in pore water (e.g., from a wider range of water depths) than currently exist. Independent temperature estimates may be provided by the chemical composition of benthic foraminiferal
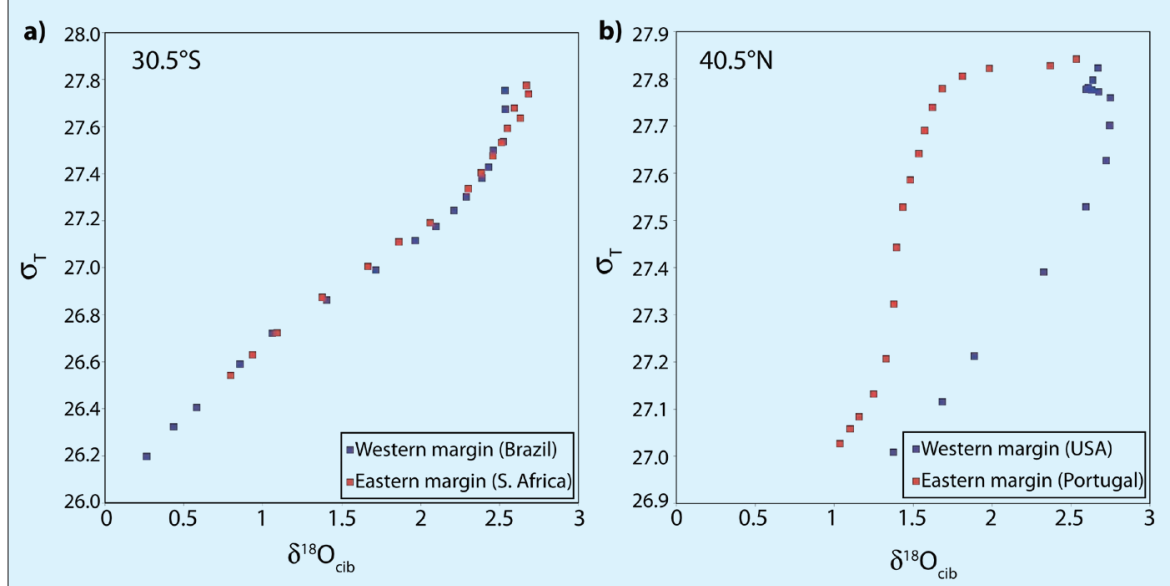

Figure 2: a) Relationship between seawater density $\left(\sigma_{T}\right)$ and calculated $\delta^{18} \mathrm{O}$ of benthic foraminifers calcifying in this water on the eastern and western margins of the South Atlantic between 200-2000 $\mathrm{m}$ water depth. Note that water mass properties are relatively similar on either side of the basin; $\boldsymbol{b})$ Relationship between seawater density $\left(\sigma_{T}\right)$ and $\delta^{18} \mathrm{O}$ of benthic foraminifers on eastern and western margins of the North Atlantic between $200-2000 \mathrm{~m}$ water depth. The input of Mediterranean Outflow Water (MOW) just south of this section produces dissimilar water mass properties on either side of the North Atlantic at $40^{\circ} \mathrm{N}$. While the impact of the MOW will be less at higher or lower latitudes, the relationship between $\delta^{18} \mathrm{O}$ of foraminifers and water density $\left(\sigma_{T}\right)$ must be determined on each margin using independent reconstructions of temperature and salinity.

tests $(\mathrm{Mg} / \mathrm{Ca}$ or $\mathrm{Sr} / \mathrm{Ca}$ ratios), although more work is needed to fully understand this emerging proxy (Elderfield et al., 2006; Marchitto et al., 2007). Given accurate temperature estimates, the $\delta^{18} \mathrm{O}$ of the water could be determined from the $\delta^{18} \mathrm{O}$ measurements on foraminifera. However, independent information on the relationship between $\delta^{18} \mathrm{O}$ of water and salinity would be needed to make accurate paleo-density estimates. The lower resolution pore-water data would be able to provide some constraints on this relationship.

\section{High-resolution reconstruction of AMOC}

Many of the ideas to explain abrupt climate changes during the last deglacial and glacial periods involve changes in the AMOC. However, we have a limited understanding of how AMOC actually varied in the geological past, in particular on millennial timescales. Reconstructing the shear of the AMOC via estimates of water density at the boundaries in the North Atlantic at millennial timescales would provide a valuable test of these ideas. Hirschi and LynchStieglitz (2006) showed that vertical density profiles on the margins of the Atlantic Ocean at only a few latitudes are necessary to reconstruct the structure and variability of the modern AMOC, provided that density estimates are sufficiently accurate. While the water mass properties on either side of the South Atlantic are relatively similar, there are important zonal differences in temperature, salinity and water $\delta^{18} \mathrm{O}$ in the upper $2 \mathrm{~km}$ in the North Atlantic, owing to the Mediterranean Outflow Water (MOW) along the eastern margin (Fig. 2).

Thus, the need for independent estimates of temperature, salinity, and/or water $\delta^{18} \mathrm{O}$ to address the ambiguity of ben- thic $\delta^{18} \mathrm{O}$ data is even more acute in the North Atlantic than in the South Atlantic. Progress in the interpretation of benthic $\delta^{18} \mathrm{O}$ data in terms of water density will likely be based on accurate paleo-temperature estimates from benthic foraminifers and pore water measurements both in the open Atlantic and the Mediterranean. An ocean-margin density-based reconstruction of the AMOC over millennial timescales is a challenge, and would require significant development on both of these fronts. However, if successful, it would be an important advance in our understanding of past variability in the AMOC and its relationship to abrupt climate change.

\#Seawater density is controlled by pressure, temperature and salinity. It is the contribution of salinity and temperature to density that can be estimated from the $\delta^{18} \mathrm{O}$ of foraminifers. Sediment core depth can be used to estimate pressure and (along with assumptions about the combined effects of temperature, salinity and pressure) the in situ density for calculations.

\section{References}

Gebbie, G. and Huybers P., 2006: Meridional circulation during the Last Glacial Maximum explored through a combination of South Atlantic d180 observations and a geostrophic inverse model, Geochemistry Geophysics Geosystems, 7: 011N07, doi:10.1029/2006GC001383.

Hirschi, J. and Lynch-Stieglitz, J., 2006: Ocean margin densities and paleoestimates of the Atlantic meridional overturning circulation: $A$ model study, Geochemistry Geophysics Geosystems, 7: 010N04.

Huybers, P., Gebbie, G. and Marchal, 0., 2007: Can Paleoceanographic Tracers Constrain Meridional Circulation Rates?, Journal of Physical Oceanography, 37: 394-407.

Lynch-Stieglitz, J., 2001: Using ocean margin density to constrain ocean circulation and surface wind strength in the past, Geochemistry Geophysics Geosystems, 2: 10.129/2001GC000208.

Lynch-Stieglitz, J., Curry, W.B., Oppo, D.W., Ninneman, U.S., Charles, C.D. and Munson, J., 2006: Meridional overturning circulation in the South Atlantic at the last glacial maximum, Geochemistry Geophysics Geosystems, 7: 010N03, 10.1029/2005GC001226.

For full references please consult:

www.pages-igbp.org/products/newsletter/ref2008_1.html 